\title{
The Hazards of Building in the Vicinity of Electromagnetic Fields: Lessons for Building Code Enforcement in Nigeria
}

\author{
C. Chuba Jon-Nwakalo Obianuju M. Jonas Chidi K. Nnenanya \\ Department of Architecture \\ Faculty of Environmental Studies, University of Nigeria, Nsukka, (Enugu Campus), Nigeria \\ Chigozie O. Mmo \\ Department of Architecture, Faculty of Environmental Sciences, \\ Nnamdi Azikiwe University, Awka, Nigeria
}

\begin{abstract}
This paper dealt with the topic of electromagnetic field (EMF) and its effects on building occupants when such buildings are located within the vicinity of the field. Two main sources of EMF, namely, high voltage power transmission lines and cellular towers, were reviewed. Empirical evidence revealed that they have a tendency to emit electromagnetic fields and they have been determined to be hazardous to building occupants. Studies have also established that when buildings are erected within an unsafe distance to the fields, occupants of such buildings become exposed to health risks. Indeed, evidence exists to show that exposure to these fields can lead to cancer in children and that men exposed to the fields are also susceptible to health risks. Studies by the International Agency for Research on Cancer (IARC) among others, assessed the carcinogenicity of radiofrequency electromagnetic fields (RF-EMF) positing that human responses to RF-EMF can occur from use of personal devices such as mobile telephones, cordless phones, Bluetooth, and amateur radios; from occupational sources such as high frequency dielectric and induction heaters, and high-powered pulsed radars. Exposures can also occur from environmental sources such as mobile phone base stations, broadcast antennas, and medical applications. This paper also examined standards for safe distances and buffers for building location with respect to EMFs and made recommendations for policy makers and building code enforcement services.
\end{abstract}

Keywords: Building Codes, Epidemiology, Carcinogenicity, Radio Frequency, Extreme Low Frequency, NonIonizing Radiation

DOI: $10.7176 / \mathrm{JETP} / 9-3-01$

Publication date:March $31^{\text {st }} 2019$

\section{INTRODUCTION}

Among the practitioners in the building industry, a building project generally begins with the selection of a particular site. Architects are usually retained by owners and developers to aid in site selection and when they perform this site selection function, they consider various characteristics of the site including, among other things, the exact location of the site, its orientation, topography, existing vegetation, accessibility, microclimate, utility availability, such as electrical power supply, telephone service and water supply. Electrical power supply is usually delivered to the building through high voltage transmission lines connected to the building at the weather head after the voltage is stepped down. Unfortunately, these high voltage transmission lines, despite their necessity and utility, sometimes pose some dangers to the building occupants, if the building is located too close to them. Similarly, cellular towers (cell towers) which are located too close to residential buildings have a tendency to emit electromagnetic fields which can be hazardous to the building occupants as well. These fields have been shown by certain studies to cause deleterious health effects, such as cancer in humans, especially, children and men (Wertheimer 1979; Ahlbom, et al 2000; IARC 2011; 2015). Indeed, the studies by the International Agency for Research on Cancer (IARC) assessed the carcinogenicity of radiofrequency electromagnetic fields (RF-EMF) positing that human responses to RF-EMF can occur from use of personal devices such as mobile telephones, cordless phones, Bluetooth, and amateur radios; from occupational sources such as high frequency dielectric and induction heaters, and high-powered pulsed radars. Exposures can also occur from environmental sources such as mobile phone base stations, broadcast antennas, and medical applications. The study also noted that most exposure to RF-EMF comes from near-field sources, the general population getting the highest exposure from transmitters close to the body, such as hand-held devices like mobile telephones.

There is no question that our society is awash with Electromagnetic Fields. As our world advances in technology with new inventions and development of new products, the society becomes rife with associated health hazards. To this extent, electromagnetic fields tend to assume ubiquitous proportions and are widespread. Much of what was previously known about them, especially, with respect to their effects on humans appeared to be speculative based on anecdotal evidence. However, in recent times, many studies have been performed to add empirical content to the hypothetical anecdotes. Some of these have been successful in validating the claims of health risks in humans while others have not been so successful. The successful studies have demonstrated the 
adverse effects of EMFs on humans. Indeed, epidemiologists were the first scientists to study the effects of EMFs on human body, especially, development of cancer (Habash 2003).

\section{Objectives of the Study}

1. The main objective of this paper is to understand the dangerous effects of EMFs on building occupants when such buildings are located within the proximity of high voltage electrical transmission lines and cell towers. This is especially relevant to the Nigerian situation where there seems to be a tendency for local building contractors to construct such buildings recklessly in the proximity of power lines and cell towers without regard to the consequences. This occurs both in urban centers but more commonly in rural areas where there is little or no oversight of building code enforcement officials.

2. An additional objective of this paper is to create awareness among the design professionals (architects, engineers and the allied professions), and contractors as to their responsibility with regard to the health, safety and welfare of the public; they need to be conscious of this fact when performing their site selection function and to properly advise their clients. These design professionals, as a rule, have responsibility to assure that the buildings they design are code-compliant with respect to the three afore mentioned objectives.

3. Third and more important, we wish to disseminate information to potential building occupants (owners and renters alike) as to the hazards of these fields.

4. Moreover, utility firms and mobile telephone companies need to be made aware of their responsibility for ensuring safe installation of their facilities to minimize hazards to the general public. On occasion, in Nigeria, these mobile telephone companies have exploited the vulnerability and ignorance of some residents by offering them what seemed to them like substantial monetary compensation for site access (authors' observations). However, such compensations would hardly make up for the potential adverse health effects that could result from such decisions.

5. Finally, one of the objectives of this study is to bring to the attention of policymakers the need for more rigorous building code enforcement in order to minimize the incidence of violations of setback requirements for high voltage power lines.

\section{What are Electromagnetic Fields?}

Electromagnetic fields (EMFs) are electric and magnetic fields emanating from the generation, distribution and utilization of electricity, mobile telephones and a variety of other sources such as radio and television broadcast towers and antennas. Electromagnetic radiation is made up of an electric and a magnetic field, pushing charged particles in the direction of the field and at right angles to it, respectively (Pool 1990). While electrical fields are easily screened, magnetic fields can easily penetrate most materials. Further, electromagnetic spectrum encompasses a wide variety of electromagnetic fields, including static fields, radio frequency fields, ultraviolet (UV) radiation, visible light and X-ray radiation (Ahlbom and Feychting 2003).

These fields occur in connection with the use of electric power, electronic surveillance devices and various other types of wireless communications. Typical examples are the high voltage electrical power transmission lines that are installed in various residential neighborhoods. In neighborhoods of high or medium density, the effects could be palpable. Studies have shown that exposure to strong fields can result in acute effects, such as burns. They have been shown to be more dangerous in children than adults. Research done four decades ago showed an association between childhood cancer mortality and the presence of power lines in the proximity of the children's homes, spurring significant public interest in the power frequency fields phenomenon (Wertheimer and Leeper 1979).

EMFs can be classified into three broad categories depending on the frequency range. They are:

1. Radio Frequency (RF) fields

2. Extremely Low Frequency (ELF) fields and

3. Very Low-Frequency (VLF) fields

The RF fields have a long wavelength with frequencies of a few centimeters or less, depending on the actual frequency. These include fields that are used for communication with mobile telephones which typically use frequencies from 450 to $2500 \mathrm{MHz}$. Environmental RF fields are characterized by their power density, measured as Watt per square meter $\left(\mathrm{W} / \mathrm{m}^{2}\right)$.

ELF fields are defined as those with frequencies up to $3 \mathrm{KHz}$, while VLF fields have frequencies ranging between $10-30 \mathrm{KHz}$. (Habash 2003).

ELF magnetic fields in the environment are usually characterized by their flux density, which is measured in units of Tesla $(\mathrm{T})$ or micro Tesla $(\mu \mathrm{T})$.

\section{Methodology}

The methodology for this research effort is based on review and analysis of archival data, largely from secondary 
sources. Scientific literature on the subject, some from primary sources while others are from secondary sources, were reviewed in order to elucidate the findings on EMF link to health effects. We reviewed the literature archives in order to glean information establishing correlationship or associative relationship between EMFs and health risks. The efforts, to some degree, uncovered definitive links with incidence of cancer in humans, especially childhood leukemia for building occupants residing within proximate distance of EMFs. While some findings show some correlationship, others, however, were lacking in confirming the hypothesis that there is a link between EMF exposure and health effects.

Our reporting is descriptive and analytical to discuss the findings based on available data. The objective is to provide a review of information related to health risks of EMF residential exposure.

\section{Literature Review}

Literature exists to validate the notion that there is health risk associated with location of buildings within the vicinity of electromagnetic fields (EMFs). To be sure, studies have established that when buildings are erected within an unsafe distance to the fields, occupants of such buildings become exposed to health risks. The strongest evidence for these risks is from exposure to fields emanating from the use of electric power (Ahlbom and Feychting 2003). Studies have been done which linked childhood cancer mortality to the presence of power lines within proximity of the children's home (IARC 2011, 2015). These fields have been shown by certain studies to cause deleterious health effects, such as cancer in humans, especially, children and men (Wertheimer 1979; Ahlbom, et al 2000; IARC 2011; 2015). Indeed, the studies by the International Agency for Research on Cancer (IARC) assessed the carcinogenicity of radiofrequency electromagnetic fields (RF-EMF) positing that human responses to RF-EMF can occur from use of personal devices such as mobile telephones, cordless phones, Bluetooth, and amateur radios; from occupational sources such as high frequency dielectric and induction heaters, and highpowered pulsed radars. Exposures can also occur from environmental sources such as mobile phone base stations, broadcast antennas, and medical applications. The study also noted that most exposure to RF-EMF comes from near-field sources, the general population getting the highest exposure from transmitters close to the body, such as hand-held devices like mobile telephones.

In conducting his research on this subject, Robert Pool (1990) posed a question as to whether there is an EMF-cancer connection. He pointed out that initial studies that found correlations between living near power lines and cancer incidence in children, reported in 1979, were easily discounted for methodical reasons. He noted that a major confounding factor is the difficulty of quantifying exposure to EMFs and other possible carcinogens, since a dose-response relationship must be established before causality can be inferred (Pool 1990).

Riadh W.Y. Habash (2003) in investigating this topic reviewed data on the health risks of EMF residential exposure. Four major areas were considered for evaluating the possible risks with emphasis on recent studies. He enumerated these as: 1) Safety Standards for EMFs; 2) Residential Field Measurement Survey; and 3) Biological and Epidemiological studies of diseases with foreseeable association with EMFs including childhood leukemia, breast cancer and pregnancy adverse outcomes. On the basis of the review findings, it was difficult to provide a robust conclusion about health risks of EMFs.

However, Ahlbom and Feychting (2003), in their study showed that "the strongest evidence for health risks is from exposure to fields generated in connection with use of electric power". They posit that with respect to fields used by telecommunications technology, there were not sufficient data to buttress the claim of correlation between the fields and health effects.

The results of epidemiological study by Wertheimer and Leeper (1979) suggested that childhood cancer mortality was associated with the existence of power lines near the children's homes "particularly with such power lines that were indicative of high magnetic field exposure". They further note that since their writing, nearly 20 studies on childhood cancer and residential exposure to ELF fields had been published, and that the studies had been of increasing methodical strengths, particularly with respect to assessment of magnetic field exposure but also with regard to selection bias and other methodical aspects (Ahlbom, Day, et al. 2000). The findings of some of these later studies somewhat confirmed the original finding, although the results might not have been identical. Nonetheless, to assess the overall evidence, a pooled analysis was performed based on primary data from the sub group of nine studies which met certain quality criteria. The principal finding of the pooled analysis was that residential magnetic field exposure in excess of $0.4 \mu \mathrm{T}$ was associated with about a doubling in the relative risk of childhood leukemia.

Besides studies linking ELF exposure with childhood cancer, there have been studies on EMF effect on cardiovascular disease. This was based on physiological experiments that indicated that "ELF magnetic fields appeared to affect heart rate variability" (Sastre, Cook, et al. 1998). Unfortunately, the results of the study failed to show evidence of correlationship with ELF exposure.

In addition to studies on EMF exposure relative to power lines, studies have been performed to show health effects of EMF due to mobile telephone usage. Some of these studies were done using records from network operators, while others combined data from the network operators and data obtained directly from users. 
EMFs generated by RF sources couple with the body, resulting in induced electric and magnetic fields and associated currents inside tissues (IARC 2011). Very importantly, the same studies posited that "holding a mobile phone to the ear to make a voice call can result in high specific RF energy absorption-rate (SAR) values in the brain, depending on the design and position of the phone and its antenna in relation to the head, and the quality of the link between the base station and phone." (IARC 2011)

An array of studies has been performed focusing on Nigeria to determine whether there is a link between EMFs and health in certain localities. For instance, Akintonwa, Busari et al (2008) examined the hazards of nonionizing radiation of telecommunication masts (cellular towers) in an urban area of Lagos. The study looked at the health effects of non-ionizing radiation and found that there are health implications of exposure to mast radiation.

Of considerable significance to this particular paper is the study by Olapeju and Farotimi (2016), which investigated the profiles of buildings located within the setback of high tension power lines (Olapeju and Farotimi 2016). The study area was located in the town of Agbado, Ogun State, Nigeria, in the vicinity of the $330 \mathrm{kVA}$ power lines. In short, these buildings were sited within the right-of-way, in violation of building codes, rules and regulations. The study objectives were varied, including, among others, to identify the characteristics of buildings encroaching on a 50-meter setback from the high tension power lines and investigate their exposure to EMF radiation. According to the authors, a remote sensing technique was used to establish the buffer of 50 meters on either side of the high tension power line in the affected area. However, the study also indicated that the 50-meter setback is a requirement of Ogun State Urban and Regional Planning Law.

The findings are palpable, demonstrating egregious consequences for the error and oddity of building under high tension power lines. One of the findings was the health effect of EMF exposure. According to the findings of the study, referring to interview with the hospital in the study area, two individuals living in the study area were diagnosed with acute lymoblastic leukemia. While the study implied some association between EMF exposure of these patients and living in the study area, definitive correlation was not established.

Neuert (2012) used testing instruments to study the safe distances to consider for EMF sources. He noted that the EMF emitted from various sources can vary significantly; indicating that in order to determine a safe distance, measurement with a special instrument called gaussmeter will be required. It is difficult, though, to predict a safe distance from power lines, although,"the strongest magnetic fields are usually emitted from high voltage transmission lines." He also pointed out that it is even more difficult to predict a safe distance from a neighborhood power distribution lines. He further indicated that "homes with a nearby transformer will sometimes have higher EMFs because the transformer is a hub and the power lines carry more electricity for a group of homes". (Neuert 2012) He also indicated that there can be stray electricity (electric current) flowing in the metal water pipes of the neighborhood, increasing the magnetic fields from both the overhead power lines and the subterranean water lines.

\section{Safe Distances and Buffers for Building Location}

Determining safe distances for electromagnetic fields are at best more conjectural than certain. Actual EMF exposure and corresponding safety distances can vary substantially and therefore, difficult to predict with precise accuracy (Neuert 2012). In-situ measurement with instruments is a requirement in order to more accurately determine EMF exposure. Due to health effects that could result from EMF exposure, it is critical that the guidelines be followed.

General Public Precautionary Levels have been established in the industry to help minimize the exposure to EMF. According to Neuert (2012), "individuals with a heightened sensitivity to electromagnetic fields or other serious health problems, such as, chronic fatigue, cancer or Lyme disease should reduce their exposure down to the much stricter EMF Hypersensitivity Advisory levels". Below is the Table of Safe Distances from EMF sources. Gaussmeter is the instrument used for measuring magnetic fields while RF Test meter is used for Cell Tower.

Table of Safety Distances from Various EMF Sources

Safety Distances from EMF Sources:

Possible EMF Safety Distances

\begin{tabular}{|c|c|c|c|}
\hline $\begin{array}{l}\text { Possible EMF Safety } \\
\text { Distances to Consider } \\
\text { For Common EMF Sources }\end{array}$ & $\begin{array}{l}\text { ELF Magnetic } \\
\text { Fields }\end{array}$ & $\begin{array}{l}\text { ELF } \\
\text { Electric Fields }\end{array}$ & $\begin{array}{l}\text { Radio } \\
\text { Frequency (RF) } \\
\text { \& Microwaves } \\
\end{array}$ \\
\hline $\begin{array}{l}\text { "General Public Precautionary } \\
\text { Levels" }\end{array}$ & $\begin{array}{l}\text { Distance to } 0.5 \\
\text { Milligauss } \\
\text { (mG) or less }\end{array}$ & $\begin{array}{l}\text { Distance to } 0.5 \\
\text { AC Volts on Skin } \\
\text { (VAC) }\end{array}$ & $\begin{array}{l}\text { Distance to } 0.10 \\
\text { Microwatts } / \mathrm{cm}^{2} \\
\left(\mu W / \mathrm{cm}^{2}\right)\end{array}$ \\
\hline $\begin{array}{l}\text { Power Lines } \\
\text { High voltage power lines (on metal towers) }\end{array}$ & $213 \mathrm{~m}(700 \mathrm{ft})$ & $\begin{array}{c}305 \mathrm{~m} \\
(1000 \mathrm{ft})\end{array}$ & \\
\hline $\begin{array}{l}\text { Neighborhood Distribution Power Lines } \\
\text { (on Wooden Poles) }\end{array}$ & $\begin{array}{l}3 \mathrm{~m} \text { to } 61 \mathrm{~m}(10 \mathrm{ft} \text { to } \\
200 \mathrm{ft})\end{array}$ & $\begin{array}{l}3 \mathrm{~m} \text { to } 18 \mathrm{~m}(10 \mathrm{ft} \\
\text { to } 60 \mathrm{ft})\end{array}$ & \\
\hline
\end{tabular}




\begin{tabular}{|c|c|c|c|}
\hline $\begin{array}{l}\text { Electric Utility Transformer } \\
\text { (on pole or ground) }\end{array}$ & $\begin{array}{c}3 \mathrm{~m} \text { to } 6 \mathrm{~m}(10 \mathrm{ft} \text { to } 20 \\
\mathrm{ft})\end{array}$ & & \\
\hline $\begin{array}{l}\text { Broadcast Towers } \\
\text { Cell towers/antennas }\end{array}$ & & & $400 \mathrm{~m}(1 / 4 \mathrm{mile})$ \\
\hline Radio and TV Broadcast Towers & & & $800 \mathrm{~m}(1 / 2 \mathrm{mile})$ \\
\hline $\begin{array}{l}\text { Electrical Panels } \\
\text { Main electric meter/service } \\
\text { Panel - Unshielded } \\
\end{array}$ & $3.05 \mathrm{~m}(10 \mathrm{ft})$ & & \\
\hline $\begin{array}{l}\text { Main Electric meter/service } \\
\text { Panel - unshielded Shielded with MuMetal }\end{array}$ & $1.524 \mathrm{~m}(5 \mathrm{ft})$ & & \\
\hline $\begin{array}{l}\text { Other electrical panels and sub-panels - } \\
\text { Unshielded }\end{array}$ & $2.4 \mathrm{~m}(8 \mathrm{ft})$ & & \\
\hline $\begin{array}{l}\text { Other electrical panels and Sub-panels } \\
\text { shielded with MuMetal }\end{array}$ & $1.2 \mathrm{~m}(4 \mathrm{ft})$ & & \\
\hline $\begin{array}{l}\text { Smart Meters (RF emitting electric utility } \\
\text { meters) }\end{array}$ & & & $12 \mathrm{~m}(40 \mathrm{ft})$ \\
\hline $\begin{array}{l}\text { Electrical Wiring } \\
\text { Romex wiring for } 15 \text { and } 20 \text { amp circuits }\end{array}$ & $.61 \mathrm{~m}(2 \mathrm{ft})$ & $1.8 \mathrm{~m}(6 \mathrm{ft})$ & \\
\hline Romex wiring for 30 to $60 \mathrm{amp}$ circuits & $1.2 \mathrm{~m}(4 \mathrm{ft})$ & $1.8 \mathrm{~m}(6 \mathrm{ft})$ & \\
\hline $\begin{array}{l}\text { Romex (BX }\} \text { wiring for } 70 \text { to } 200 \text { amp } \\
\text { circuits }\end{array}$ & $1.8 \mathrm{~m}(6 \mathrm{ft})$ & $1.8 \mathrm{~m}(6 \mathrm{ft})$ & \\
\hline MC (BX) wiring for 30 to 60 amp circuits & $0.61 \mathrm{~m}(2 \mathrm{ft})$ & & \\
\hline MC (BX 3 wiring for 70 to $200 \mathrm{amp}$ circuits & $1.2 \mathrm{~m}(4 \mathrm{ft})$ & & \\
\hline MC (BX) wiring for 15 to $20 \mathrm{amp}$ circuits & $1.8 \mathrm{~m}(6 \mathrm{ft})$ & & \\
\hline $\begin{array}{l}\text { Lighting } \\
\text { Fluorescent lamps and fixtures }\end{array}$ & $\begin{array}{l}1.2 \mathrm{~m} \text { to } 2.4 \mathrm{~m}(4 \mathrm{ft} \text { to } 8 \\
\mathrm{ft})\end{array}$ & $1.8 \mathrm{~m}(6 \mathrm{ft})$ & \\
\hline Compact Fluorescent Lamps (CFL) & $0.61 \mathrm{~m}$ to $1.2 \mathrm{~m} \mathrm{(4 \textrm {ft } )}$ & $1.8 \mathrm{~m}(6 \mathrm{ft})$ & \\
\hline LED lamps & $\begin{array}{l}0.61 \mathrm{~m} \text { to } 1.8 \mathrm{~m}(2 \text { to } 6 \\
\mathrm{ft})\end{array}$ & $1.8 \mathrm{~m}(6 \mathrm{ft})$ & \\
\hline $\begin{array}{l}\text { The transformers and features for low- } \\
\text { voltage lighting }\end{array}$ & $\begin{array}{l}0.61 \mathrm{~m} \text { to } 1.8 \mathrm{~m}(2 \text { to } 6 \\
\mathrm{ft})\end{array}$ & $1.8 \mathrm{~m}(6 \mathrm{ft})$ & \\
\hline Incandescent light bulbs and fixtures & $0.305 \mathrm{~m}(1 \mathrm{ft})$ & $1.8 \mathrm{~m}(6 \mathrm{ft})$ & \\
\hline $\begin{array}{l}120 \text { volt halogen bulbs and fixtures (not low } \\
\text { volt halogen) }\end{array}$ & $0.305 \mathrm{~m} \mathrm{(1 \textrm {ft } )}$ & $1.8 \mathrm{~m}(6 \mathrm{ft})$ & \\
\hline $\begin{array}{l}\text { Appliances } \\
\text { Microwave ovens }\end{array}$ & $2.4 \mathrm{~m}(8 \mathrm{ft})$ & $1.8 \mathrm{~m}(6 \mathrm{ft})$ & $9 \mathrm{~m}(30 \mathrm{ft})$ \\
\hline Refrigerators & $1.8 \mathrm{~m}(6 \mathrm{ft})$ & $1.8 \mathrm{~m}(6 \mathrm{ft})$ & \\
\hline Most other Electrical appliances & $1.2 \mathrm{~m}(4 \mathrm{ft})$ & $1.8 \mathrm{~m}(6 \mathrm{ft})$ & \\
\hline Most small plug in transformers & $1.2 \mathrm{~m}(4 \mathrm{ft})$ & $1.8 \mathrm{~m}(6 \mathrm{ft})$ & \\
\hline Electrical Fans & $1.8 \mathrm{~m}(6 \mathrm{ft})$ & $1.8 \mathrm{~m}(6 \mathrm{ft})$ & \\
\hline Electrical heaters & $2.4 \mathrm{~m}(8 \mathrm{ft})$ & $1.8 \mathrm{~m}(6 \mathrm{ft})$ & \\
\hline Spa \& hot tubs-heaters and pumps & $2.4 \mathrm{~m}(8 \mathrm{ft})$ & $1.8 \mathrm{~m}(6 \mathrm{ft})$ & \\
\hline $\begin{array}{l}\text { Electronics } \\
\text { Most computer hardware (non- wireless) }\end{array}$ & $1.2 \mathrm{~m}(4 \mathrm{ft})$ & $1.8 \mathrm{~m}(6 \mathrm{ft})$ & \\
\hline LED and LCD computer monitors & $0.61 \mathrm{~m}(2 \mathrm{ft})$ & $1.8 \mathrm{~m}(6 \mathrm{ft})$ & \\
\hline LED, LCD and Plasma televisions & $1.2 \mathrm{~m}(4 \mathrm{ft})$ & $1.8 \mathrm{~m}(6 \mathrm{ft})$ & \\
\hline Stereo equipment, other small electronics & $1.2 \mathrm{~m}(4 \mathrm{ft})$ & $1.8 \mathrm{~m}(6 \mathrm{ft})$ & \\
\hline $\begin{array}{l}\text { Wireless Technologies } \\
\text { Cell phones }\end{array}$ & & & $12 \mathrm{~m}(40 \mathrm{ft})$ \\
\hline Cordless phones & & & $12 \mathrm{~m}(40 \mathrm{ft})$ \\
\hline Cordless phone base & $1.2 \mathrm{~m} \mathrm{(4 \textrm {ft } )}$ & & $12 \mathrm{~m}(40 \mathrm{ft})$ \\
\hline Wireless routers, Wi-Fi routers & $1.2 \mathrm{~m}(4 \mathrm{ft})$ & $1.8 \mathrm{~m}(6 \mathrm{ft})$ & $12 \mathrm{~m}(40 \mathrm{ft})$ \\
\hline Wireless Keyboard and mouse & & & $12 \mathrm{~m}(40 \mathrm{ft})$ \\
\hline Baby monitors & & & $12 \mathrm{~m}(40 \mathrm{ft})$ \\
\hline
\end{tabular}

Source: Neuert,Michael, R. "What Distance is Safe", www.EMFinfo.org

Note 1 The General Public Precautionary Level is a precautionary guideline for those who wish to be proactive 
with EMFs and protect their health. A safety level of $0.5 \mathrm{mG}$ is suggested to provide a margin of safety below 1.0 milligauss $(\mathrm{mG})$ linked to childhood cancer in studies.

Note 2 Safety distance from an EMF source is simply the measured distance needed to reduce human exposure down to some desired safety level for most cases. But safety distances are difficult to predict because many factors can cause variations in the actual level of EMFs emitted, and thus variation in the actual safety distances needed. The distances shown here are likely to reduce the EMFs exposures to the safety level shown at the top of the chart, for the majority of the situations. In many cases the actual distance needed will be less than shown in this chart but in some cases an even greater distance may be needed. It is advisable to measure on-site with an EMFs test meter to determine the actual safety distance.

Note 3 Individuals with heightened sensitivity to electromagnetic fields - or other serious health issue such as cancer, chronic fatigue or Lyme disease - may wish to reduce their EMF exposure even further, perhaps down to the stricter EMF Hypersensitivity Advisory levels.

Not 4 The suggestions for safety distances in this chart are generally based on Michael Neuert's professional on-site testing on the various EMF sources in the San Francisco Bay area since 1992. Actual EMF emissions and thus corresponding the safety distance can vary greatly and are difficult to predict. To better determine the safety distances, it is always advisable to measure the actual EMF levels with an appropriate EMF test meter whenever possible.

\section{Implications for Policy and Lessons for Code Enforcement}

Having observed the effects of RF-EMF on humans, and having assessed the risk, particularly with respect to its carcinogenicity and other ailments, it is imperative for policymakers, as a matter of urgent public policy, to strengthen existing laws and promulgate new codes, where they are non-existent, which will discourage contractors and builders from building within the vicinity of EMFs. In other words, codes, rules and regulations, which prohibit trespassing of established high voltage electrical transmission lines and base station rights-of-way, must be made clear to the public. Since scientists have observed that the exposure levels from base stations are exceeded by about a thousand times by exposure levels from the phones themselves, it will be sensible to advice caution in the use of mobile phones as well.

Many scholars are careful not to offer policy advice on EMF exposure. This inclination is somewhat borne out of the uncertainty that is associated with research on this subject. This paper does not as well offer any such advice, however, as a voluntary precautionary measure, public health professionals, design professionals (including architects and engineers) regulatory authorities, code enforcement officials, electric utilities and individuals are encouraged to engage in advocacy to minimize EMF exposures wherever possible. (Habash 2003)

As indicated earlier, licensed design professionals such as architects and engineers, have an obligation by virtue of their license, to protect the public health, safety and welfare. This is the creed of their licensure as design professionals.

\section{Conclusion}

This paper analyzed the subject of electromagnetic field (EMF) relative to its effects on building occupants where such buildings are located within the vicinity of EMFs. Electromagnetic fields are defined as electric and magnetic fields emanating from the generation, distribution and utilization of electricity, mobile telephones and a variety of other sources such as radio and television broadcast towers and antennas. Electromagnetic radiation is made up of an electric and a magnetic field, pushing charged particles in the direction of the field and at right angles to it, respectively. When buildings are located close to these sources, the building occupants are exposed to health risks. Specifically, studies have shown that exposure to these fields can lead to cancer in children and that men exposed to the fields are susceptible to health risks. Moreover, studies by the International Agency for Research on Cancer (IARC) assessed the carcinogenicity of radiofrequency electromagnetic fields (RF-EMF) and posited that human responses to RF-EMF can occur from use of personal devices such as mobile telephones, cordless phones, etc.

There was a five-fold objective to this study, namely:

1. To understand the perils of EMF exposures relative to building occupants.

2. To create awareness among design professionals (architects, engineers and the allied professions) as to their responsibility with regard to the health, safety and welfare of the public.

3. To disseminate information to potential building occupants (owners and renters alike) with respect to the hazards of EMFs.

4. To raise awareness among utility companies about their responsibility for ensuring safe installation of their facilities to minimize hazards to the general public.

5. To raise awareness among policymakers on the need for more rigorous building code enforcement relative to the violation of high voltage power line right of way and buffers.

We also reviewed the safe distances and buffers for building locations. A table of safety distances from various EMF sources is attached. 


\section{References}

1. Ahlbom, Anders and Maria Feychting, "Electromagnetic Radiation: Environmental Pollution and Health". British Medical Bulletin, 68: 1 (December 2003): 157-165

2. Akintonwa, A., A. Busari et al, "The Hazards of Non-Ionizing Radiation of Telecommunication Mast in an Urban Area of Lagos, Nigeria" African Journal of Biomedical Research. 12: 1 (January 2009): 31-35

3. Baan, Robert, Yaan Grosse, et al "Carcinogenicity of Radiofrequency Electromagnetic Fields". International Agency for Research on Cancer Monograph Working Group, www.thelancet,com 12: (July 2011): 624-626

4. Neuert, Michael R. "What Distance is Safe?" www.emfinfo.org (2012)

5. Olapeju, O.O. and A. O. Farotimi, "Profile of Buildings on the Setback of High Tension Power Lines in Agbado, Ogun State". Research Gate, Conference Paper, (January 2016)

6. Pool, Robert. "Is there an EMF-Cancer Connection" Science, 249: 4973 (1990): 1096

7. Sivani, S. and D. Sudarsanam, "Impacts of Radio-Frequency Electromagnetic Field (RF-EMF) from Cell Phone Towers and Wireless Devices on Biosystem and Ecosystem - A Review”. Biology and Medicine. 4:4 (January 2013): 202-216 